\title{
Comparative Evaluation of Efficacy of Three Different Rotary Retreatment Systems with Manual Instrumentation in Removing Gutta-Percha from Root Canals - An In Vitro Study
}

\author{
Aparna V. Muraleedhar ${ }^{1}$, Sarvapelli Venkata Satish², Ashwini M. Patil ${ }^{3}$, Suresh Kumar Kovvuru ${ }^{4}$, Snehalatha Patil ${ }^{5}$ \\ 1, 2, 3, 4, 5 Department of Conservative Dentistry and Endodontics, \\ Navodaya Dental College, Raichur, Karnataka, India.
}

\section{ABSTRACT}

\section{BACKGROUND}

The primary goal of endodontic retreatment is to take out the root filling completely to ensure that the canal is completely cleaned. Gutta percha removal using hand instruments is a time-consuming procedure and tedious for the operator. Therefore, various nickel titanium instruments have been introduced for the effective retrieval of gutta percha. This study was done to compare the efficacy of three different rotary systems compared with manual instrumentation for gutta percha removal during retreatment.

\section{METHODS}

Forty-eight single rooted premolars were prepared and obturated using gutta percha and AH Plus sealer using lateral compaction technique. Samples were randomly divided into four groups of 12 specimens each. Group 1 was retreated with Hedstrom Files (H-Files), group 2 was retreated with pro taper universal retreatment files (PTUR), group 3 with R-Endo retreatment files and group 4 with Neoendo retreatment files. Time taken for the retreatment was recorded for each tooth using a stopwatch. The samples were sectioned longitudinally and observed under a stereomicroscope. Digital images were taken and analysed using digital image analysing software. The data was statistically analysed using Kruskal-Wallis and Post-hoc Mann-Whitney test.

\section{RESULTS}

The Neoendo group showed significantly lower amount of residual material compared to PTUR, R-Endo and the H-Files $(\mathrm{P}=0.00)$. The maximum residual material was observed in the $\mathrm{H}$ file group. The time taken for gutta percha removal was least for the Neoendo group followed by PTUR, R-Endo and H-Files.

\section{CONCLUSIONS}

None of the instruments were able to remove the filling material completely. Gutta percha removal using Neoendo and protaper universal retreatment files were faster and more efficient compared to REndo and H files.

\section{KEY WORDS}

Endodontic Retreatment, Protaper Universal Retreatment Files, R-Endo, Neoendo, HFiles
Corresponding Author: Dr. Sarvapelli Venkata Satish, Professor and Head, Department of Conservative Dentistry and Endodontics, Navodaya Dental College, Raichur, Karnataka, India.

E-mail: aparnamurali24@gmail.com

DOI: $10.14260 /$ jemds $/ 2021 / 219$

How to Cite This Article:

Muraleedhar AV, Satish SV, Patil AM, et al. Comparative evaluation of efficacy of three different rotary retreatment systems with manual instrumentation in removing gutta-percha from root canals - an in vitro study. J Evolution Med Dent Sci 2021;10(14):1025-1029, DOI 10.14260/jemds/2021/219

Submission 15-10-2020, Peer Review 08-02-2021, Acceptance 15-02-2021, Published 05-04-2021.

Copyright (C) 2021 Aparna V. Muraleedhar et al. This is an open access article distributed under Creative Commons Attribution License [Attribution 4.0 International (CC BY 4.0)] 


\section{BACKGROUND}

The long term prognosis of endodontic treatment is dependent on the meticulous debridement of the root canal systems followed by three dimensional obturation. The prime reason for the failure of root canal therapy is the tenacity of the pathogens within the intricacies of root canal system. The nonsurgical retreatment approach is considered as a choice for the management of failed endodontic cases as it is a more conservative and feasible procedure. ${ }^{1}$ The primary goal of endodontic retreatment is to take out the root filling completely to ensure that the canal is completely cleaned. ${ }^{2}$

Gutta percha with varieties of sealers are the most often used root filling material to produce a hermetic seal. Root filling material can be removed during retreatment using endodontic hand files, nickel titanium rotary instruments, ultrasonic tips and files, heat carrying instruments, and chemical solvents. ${ }^{3}$ Gutta percha removal using hand instruments is time consuming procedure and tedious for the operator. ${ }^{4}$ Therefore, various nickel titanium instruments have been introduced for the effective retrieval of gutta percha. ${ }^{1}$

The protaper universal retreatment instrument (DentsplyMaillefer, Ballaigues, Switzerland) comprise of three files (D1, D2, D3) each with varying tapers and have a convex triangular cross section. D1 file (size 30, 0.09 taper) has a length of $16 \mathrm{~mm}$. It has an active cutting tip that aids initial penetration into the root filling material. D2 file (size 25, 0.08 taper) has a length of $18 \mathrm{~mm}$ and is used in the middle third. D3 file (size 20 , taper 0.07 ) of $22 \mathrm{~mm}$ length is used till the apical third. 1,4

R-Endo instruments (Micro-Mega, Basancon, France) consist of Rm, Re, R1, R2 and R3 are used in a gentle in and out motion. Rm (size 25, $4 \%$ taper) used first creates a pathway for the alignment of next instrument. Re (size 25, $12 \%$ taper) removes the initial 2 to $3 \mathrm{~mm}$ of obturation material, R1 (size 25, 0.08 taper) and R2 (size 25, 0.06 taper) are used at the coronal and middle third respectively and R3 is used till the working length. ${ }^{5}$

Neoendo retreatment files (Orikam Healthcare, India) consist of three instruments: N1, N2 and N3 which are 16, 18 and $25 \mathrm{~mm}$ in length respectively. $\mathrm{N} 1$ (size 30, 0.09 taper) is used at the coronal third. N2 (size 25, 0.08 taper) is used at the middle third. N3 (size 20, 0.07 taper) is used till the apical third. ${ }^{6}$

The purpose of this study was to compare the efficacy of three different rotary systems, protaper universal retreatment files, R-Endo and Neoendo retreatment files with that of $\mathrm{H}$ files for gutta percha removal during retreatment.

\section{METHODS}

\section{Specimen Selection}

Following the approval from the institutional ethical committee, this in vitro comparative study was conducted at our hospital from the month of October 2019 to January 2020. 48 single rooted extracted mandibular premolars were selected. Soft tissue and calculus were mechanically removed from the root surfaces with a periodontal scaler. The samples were kept in $0.5 \%$ chloramine-T solution for 24 hours for disinfection. Access cavities were prepared and a size $10 \mathrm{~K}$ file
(Dentsply Maillefer, Ballaigues, Switzerland) was inserted in the root canal until it was visualized at the apex. Working length was established by subtracting $1 \mathrm{~mm}$ from this measurement. The samples were decoronated by means of a diamond disk to achieve a standard size of $15 \mathrm{~mm}$.

\section{Canal Preparation and obturation}

Canal reparation was performed using step back technique to size $30 \mathrm{~K}$ file at working length, step back preparation was done till size $45 \mathrm{~K}$ file. Final coronal flaring was done with Glades Glidden drills (Dentsply Maillefer, Ballaigues, Switzerland) size 2 and 3. During instrumentation, all the canals were irrigated with $5.25 \% \mathrm{NaOCl}, 17 \%$ EDTA and finally with saline. The root canals were dried with paper points and obturated with gutta percha (Dentsply-Maillefer, Ballaigues, Switzerland) and AH Plus sealer (Dentsply De Tray, Konstanz, Germany) using lateral compaction technique. Access cavities were temporarily sealed with Cavit (ESPE, Dental Seefeld, Germany). The specimens were stored at 37 degrees centigrade in $100 \%$ humidity in an incubator for 4 weeks to allow sealer to set completely.

\section{Retreatment Technique}

Teeth were randomly divided into four groups of 12 specimens each. Xylene was used as a solvent to soften the gutta percha during retreatment. Canals were irrigated with $2.5 \%$ sodium hypochlorite after each instrument change. When no traces of gutta percha and sealer were found on the surface of the instrument or in the irrigating solution, retreatment was considered complete. A stop watch was used to calculate the retreatment time.

\section{Group 1 - Hedstrom Files}

Gutta percha was removed from the coronal portion of the canal by using Gates Glidden drill size 2 and 3. Xylene was placed in the canal and Hedstrom files (Dentsply Maillefer, Ballaigues, Switzerland) sizes 35, 30 and 25 were used in a circumferential quarter turn push pull motion to remove the root fillings from the middle and apical portions until the original working length had been reached.

\section{Group 2 - Protaper Universal Retreatment Files (PTUR)}

The root canals were instrumented in a crown down manner in a brushing motion. The rotational speed was set at $500 \mathrm{rpm}$ as per manufacturer's recommendation. D1, D2 and D3 were used in a sequential manner to reach the established working length.

\section{Group 3 - R-Endo Retreatment Files}

R-Endo files were used in a gentle in and out motion at a constant speed of $300 \mathrm{rpm}$ as per manufacturer's recommendation. The $\mathrm{Rm}$ stainless steel hand file was used with $1 / 4$ turn pressure to allow the alignment of the next instrument. The Re instrument was used to remove the first 2 $3 \mathrm{~mm}$ of the filling. R1 and R2 instruments were used to onethird and two-third of the estimated working length 
respectively. R3 was used at the working length with circumferential filing action.

\section{Group 4 - Neoendo Retreatment Files}

Neoendo retreatment files were used in a sequential manner using a light apical pressure at a constant speed of $350 \mathrm{rpm}$ as per the manufacturer's instruction. Neoendo retreatment files N1, N2 and N3 were used for the coronal, middle and apical one third respectively using crown down technique.

\section{Analysis of Residual Gutta Percha}

Roots were grooved longitudinally in buccolingual direction, into two halves using a diamond disc and split into two halves with a chisel. The specimens were observed under a stereomicroscope at $12.5 \mathrm{X}$ magnification and images were captured with a digital camera and were analysed using digital image analysing software, Image Pro v10 (media cybernetics) [Figure 1]. For practical purposes no attempt was made to differentiate between gutta percha and sealer remnants. The retreatment time was measured for each tooth using a stopwatch. The percentage of residual filling material in the root canal walls was calculated using the following equation -

The percentage of residual filling material

$$
=\frac{\text { Area of the remnant }}{\text { Area of the canal wall }} \times 100
$$

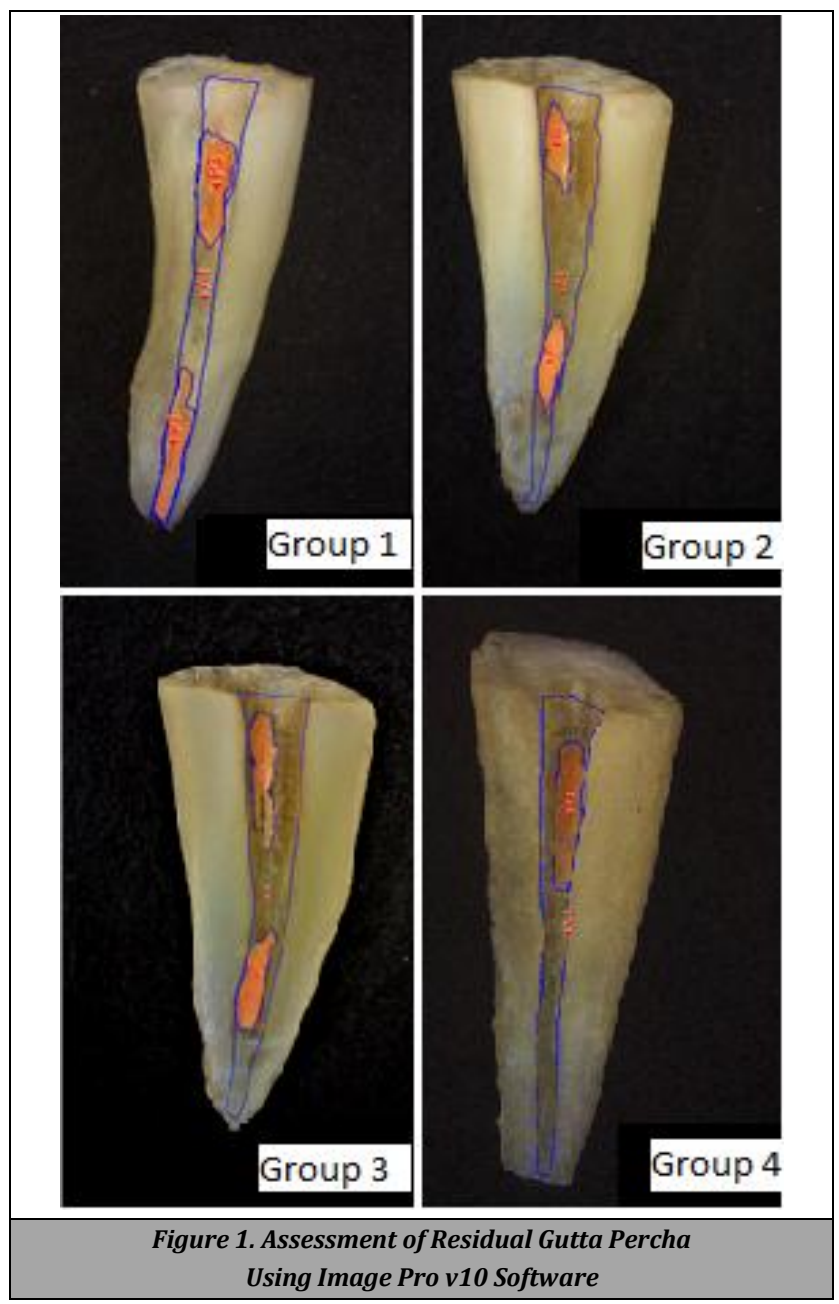

\section{Statistical Analysis}

Data obtained was subjected to normalcy and Sharpiro Wilk test which showed a non-normal data distribution. Hence, non-parametric tests were applied. Kruskal Wallis test was applied to check the statistical difference of mean percentage of total gutta percha remnant and retreatment time among the groups. Post-hoc-Man-Whitney test was used for pair wise comparison of groups. SPSS (Statistical Package for Social Sciences) software was used to perform statistical analysis.

\section{RESULTS}

Remnants of filling material were observed in all the groups. Specimens retreated with the Neoendo retreatment files left significantly less residual material followed by protaper universal retreatment system, R-Endo retreatment files and $\mathrm{H}$ files. Statistically significant difference was noted in the amount of residual filling material among all the groups $(\mathrm{P}=$ 0.00) [Table 1]. The mean time taken for retreatment was less for the Neoendo group followed by PTUR, R-Endo and H files. Statistically significant difference was found among all the groups [Table 2]. Post-hoc-Man-Whitney test was applied for intergroup comparison of gutta percha remnants and time taken; and statistically significant difference was seen between all the groups $(\mathrm{P}=0.00)$ [Table 3].

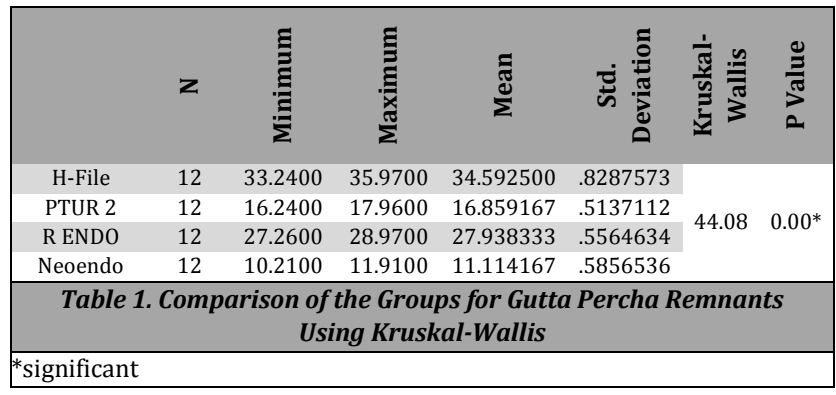

\begin{tabular}{|c|c|c|c|c|c|c|c|}
\hline & $z$ & E & 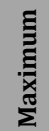 & 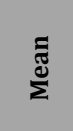 & 远 & 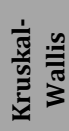 & $\frac{0}{\stackrel{\pi}{\pi}}$ \\
\hline H-File & 12 & 374 & 450 & 408.83 & 24.453 & \multirow{4}{*}{44.09} & \multirow{4}{*}{$0.00^{*}$} \\
\hline PTUR 2 & 12 & 179 & 199 & 189.08 & 6.501 & & \\
\hline R ENDO & 12 & 256 & 290 & 275.75 & 11.387 & & \\
\hline Neoendo & 12 & 124 & 143 & 135.50 & 5.617 & & \\
\hline \multicolumn{8}{|c|}{$\begin{array}{l}\text { Table 2. Comparison of the Groups for Retreatment Time } \\
\text { Using Kruskal-Wallis }\end{array}$} \\
\hline \multicolumn{8}{|c|}{ *significant } \\
\hline
\end{tabular}

\begin{tabular}{|cccccc|}
\hline \multirow{5}{*}{} & \multicolumn{3}{c}{ GP } & \multicolumn{2}{c|}{ Time } \\
H-file & Mean Diff & P-Value & Mean Diff & P-Value \\
& R ENDO & 17.73 & $0.00^{*}$ & 219.75 & $0.00^{*}$ \\
& Neoendo & 6.65 & $0.00^{*}$ & 133.08 & $0.00^{*}$ \\
PTUR 2 & R ENDO & -11.47 & $0.00^{*}$ & 273.33 & $0.00^{*}$ \\
& Neoendo & 5.74 & $0.00^{*}$ & -86.66 & $0.00^{*}$ \\
R ENDO & Neoendo & 16.82 & $0.00^{*}$ & 53.58 & $0.00^{*}$ \\
\hline \multicolumn{5}{|c|}{ Table 3. Post-Hoc Mann-Whitney for } \\
\hline *P-value set significant at 0.05 / 4 = 0.025 \\
\hline
\end{tabular}




\section{DISCUSSION}

Complete removal of root filling material from the canals is essential for successful nonsurgical retreatment as it denudes the residual necrotic tissue or bacteria that may be responsible for the persistent inflammation, thus allowing further cleaning and obturation of the root canal system.7,8 Various studies have shown the increased efficacy and reduced treatment time with NiTi rotary instruments compared to hand instruments during retreatment. ${ }^{1}$ Roots were decoronated to standardise the samples and teeth with straight canals were selected for the study to minimise the variations in the root canal morphology.1,6

Various methods including radiographs, clearing method, cone beam computed tomography (CBCT), sectioning and visualising under stereomicroscope have been used to assess the residual material on the canal walls. ${ }^{1,9}$ The current study involved longitudinal cleaving of the samples and its examination under stereomicroscope at a magnification of $12.5 \mathrm{X}$. This method is regarded simple and efficient as the distance between the sample and the device is consistent, enabling the standardisation of the image. ${ }^{9}$ The results obtained were quantitative (expressed in $\mathrm{mm}^{2}$ and percentages). ${ }^{10}$

The results of this study support the results of the previous studies that the retreatment techniques left some remnants within the root canal. ${ }^{10}$ Karamifar $\mathrm{K}$ et al. in their study reported that rotary instrumentation was more efficacious than hand instrumentation for gutta percha removal. ${ }^{11}$ In the current study, on assessing the total percentage of residual material, Neoendo files showed maximum efficacy followed by PTUR, R-Endo and $\mathrm{H}$ files. The time taken for retreatment was also less for Neoendo retreatment files compared to the other retreatment files.

Solvent has been used in the study to soften the gutta percha. ${ }^{7}$ Using solvents during the retreatment procedure is controversial as it may result in the inadvertent removal of gutta percha and leaving behind a film of residue on the canal walls.1,2,7 Chloroform is one of the most favoured solvent for gutta percha removal due to its ability to rapidly dissolve gutta percha. It is a class $2 \mathrm{~B}$ carcinogenic material and its use is controversial, therefore the use of alterative solvents such as xylene, halothane, orange oil, and tetra chloro ethylene has been suggested. ${ }^{7}$ Xylene has been used in the present study as the gutta percha solvent. Xylene dissolves gutta percha slowly and allows better elimination of gutta percha rather than liquidized gutta percha.7,8

The cutting efficacy of Protaper Retreatment files may be attributable to its design. D1, D2, D3 have progressive tapers and lengths. ${ }^{2}$ They have a convex triangular cross section. ${ }^{5}$ The PTUR files tend to pull the gutta percha into the flutes and lead it towards the canal orifice. ${ }^{2}$ Also, these engine driven files produces frictional heat which can cause the plasticization of gutta percha and its easier removal. ${ }^{2}$

The R-Endo instruments are particularly designed for retreatment and comprise a stainless steel $\mathrm{Rm}$ hand file and four NiTi files. They have a triangular cross-section with equally spaced cutting edges with no radial angle and active tip. ${ }^{8}$ The file has improved flexibility owing to its lesser core structure thus improving its flexibility and the files are centred within the canal especially at the apical third. ${ }^{5}$ Das $\mathrm{S}$ et al. in their study concluded that protaper universal retreatment instrumentation was more efficient than the R-Endo instruments. The effectiveness was attributed to the convex triangular cross section of PTUR which renders it a larger internal area for the removal of filling material. ${ }^{4}$

$\mathrm{H}$-files have a positive rake angle that facilitate gutta percha removal on withdrawal strokes. Compared to rotary files, hand files are more rigid and stiffer and their use till the working length can lead to procedural complications like ledge, transportation and perforation of the canals. ${ }^{5}$ Khalilak $\mathrm{K}$ et al. in their study reported than Protaper universal retreatment files showed better efficacy than $\mathrm{H}$ files in removal of gutta percha. This is because Protaper files D1, D2, D3 (9 \%, $8 \%, 7 \%$ taper respectively) have larger cross section compared to $2 \%$ tapered $\mathrm{H}$-files thus, removing more filling material. ${ }^{12}$

The Neoendo files have a parallelogram cross section and a positive rake angle. ${ }^{6}$ The parallelogram cross section limits the contact between the file and the dentin to only one or two points at any given cross section. This will subsequently reduce the binding and makes sure that there is little or no screwing in, thus, improving the safety and cutting efficiency. The added space around the instrument ensures room for improved debris removal. ${ }^{13}$ Also it has an active cutting tip which helps in easy initial penetration. In the present study, residual gutta percha left after retreatment with the Neoendo files was significantly less than the PTUR and R-Endo group. ${ }^{6}$ This finding is in accordance with that reported by Antony JM et al.

\section{CONCLUSIONS}

Within the limitations of this in-vitro study, it was seen that all the instruments left residual obturation material inside the root canal wall. On evaluation of total percentage of residual material, Neoendo files showed maximum efficacy followed by PTUR, R-Endo and $\mathrm{H}$ files. The time needed for retreatment was also less for the Neoendo retreatment files compared to the other retreatment files.

Data sharing statement provided by the authors is available with the full text of this article at jemds.com.

Financial or other competing interests: None.

Disclosure forms provided by the authors are available with the full text of this article at jemds.com.

\section{REFERENCES}

[1] Joseph M, Ahlawat J, Malhotra A, et al. In vitro evaluation of efficacy of different rotary instrument systems for gutta percha removal during root canal retreatment. J Clin Exp Dent 2016;8(4):355-60.

[2] Gu LS, Ling JQ, Wei X, et al. Efficacy of ProTaper Universal rotary retreatment system for gutta-percha removal from root canals. Int Endod J 2007;41(4):288-95.

[3] Tomar AK, Pyasi SK, Dubey S, et al. To compare the efficacy of different file systems to remove filling material during root canal retreatment utilizing stereomicroscope: an in vitro study. Int J Appl Dent Sci 2018;4(2):154-7. 
[4] Das S, De Ida A, Das S, et al. Comparative evaluation of three different rotary instrumentation systems for removal of gutta-percha from root canal during endodontic retreatment: an in vitro study. J Conserv Dent 2017;20(5):311-6.

[5] Ashraf K, Noushad MC, Sebastian A, et al. Evaluation of efficacy of three different rotary systems in removal of gutta-percha from root canal during retreatment-an in vitro CBCT study. Int J Recent Sci Res 2019;10(6):329259.

[6] Antony JM, Kudva AR, Shetty HK, et al. Comparative efficacy of three different retreatment rotary instrument systems for removal of gutta-percha from root canals: a comparative in vitro study. Indian J Public Health Res Dev 2019;10(4):272-7.

[7] Bhagavaldas MC, Diwan A, Kusumvalli S, et al. Efficacy of two rotary retreatment systems in removing gutta-percha and sealer during endodontic retreatment with or without solvent: a comparative in vitro study. J Conserv Dent 2017;20(1):12-6.

[8] Lalit P, Godara N, Varma KR. Evaluation of efficiency of three NiTi instruments in removing gutta-percha from root canal during retreatment-an in vitro study. Endodontology 2012;3:4.
[9] Ali A, Hussain S, Metgud S, et al. Comparative assessment of manual, rotary and reciprocating instruments for removal of root fillings, using stereomicroscope: an in vitro study. Bangladesh Medical Research Council Bulletin 2019;45(1):54-61.

[10] Kumar P, Sood H, Bhat SP, et al. Comparison of efficiency of manual (H-Files) and two rotary niti retreatment systems (Mtwo R files and HyFlex NT files) in removing Gutta-percha from root canals obturated with two different sealers by using stereomicroscope-an in vitro study. Endodontology 2017;29(2):95-100.

[11] Karamifar K, Mehrasa N, Pardis P, et al. Cleanliness of canal walls following gutta-percha removal with hand files, RaCe and RaCe plus XP-Endo finisher instruments: a photographic in vitro analysis. Iran Endod J 2017;12(2):242-7.

[12] Khalilak Z, Vatanpour M, Dadresanfar B, et al. In vitro comparison of gutta-percha removal with $\mathrm{H}$-file and ProTaper with or without chloroform. Iran Endod J 2013;8(1):6-9.

[13] De Menezes SE, Batista SM, Lira JO, et al. Cyclic fatigue resistance of WaveOne Gold, ProDesign R and ProDesign logic files in curved canals in vitro. Iran Endod J 2017;12(4):468-73. 